thin gold layer on a palladium alloy is used. For the dry circuit part of the relays the gold layer guarantees a high contact reliability, while the load circuit, in which the formation of brown powder is less critical, is handled by the more erosion-resistant palladium alloy.

Selectively electroplated strip is preferredly used for applications where a thin layer on a relatively thick support material is needed such as, for instance, in the manufacture of connectors. One advantage of this selectively electroplated material is the fact that thin gold layers can also be applied to support material such as beryllium-copper or thermobimetals on which it is quite difficult to apply the contact material by any other method.

For the future it is foreseeable that even more stress will have to be put on the design of contact parts so as to arrive at solutions which combine efficient production techniques with minimum gold consumption for the intended service requirements. In this connection it may become necessary for many applications to reconsider the present requirements and fit them more closely to the expected service life of the other components in electrical and electronic appliances. In some cases this could mean that established quality standards will be lowered if detailed product analysis shows that the present requirements result in contact parts which last considerably longer than the other components. In other cases it may be useful to increase the projected service life of the contact parts even though this may lead to higher initial costs.

In the field of connectors and sliding contacts considerable research activity will have to go into the study of the mechanism of wear so that the service life of contact parts can be increased by minimising the losses of contact material due to wear. One typical example of this line of thought is the use of relatively thick nickel underlayers below quite thin gold layers. These nickel underlayers act not only as a very effective diffusion barrier for base metal atoms from the support material, which is most important for extended life at elevated temperatures, but also bring considerably improvements in the service life of a gold alloy layer of a given thickness $(10,11)$. Conversely this principle may, of course, be used to reduce the thickness of a gold deposit on a contact part intended for a given service life.

Parallel with detailed investigations into the mechanisms of wear the studies of the tarnishing behaviour of gold alloys will have to be intensified so that the probability of contact failure with contact alloys of reduced gold contact may be further decreased. For both fields of research a very close cooperation between contact manufacturers and producers of electrical and electronic appliances will be necessary in order to achieve optimum results, since the behaviour of contact materials is very often quite strongly dependent on the design of the devices in which they are used.

\section{References}

1 D. L. Meadows et al., "The Limits to Growth" Earth Island, London, 1972

2 R. Holm, "Electric Contacts", 4th Edition, SpringerVerlag, Berlin 1967

3 A. Keil, "Werkstoffe für elektrische Kontakte" Springer-Verlag, Berlin, 1960

4 W. H. Abbott, Proc. Holm Seminar, 1969, 1

$5 \mathrm{H}$. W. Hermance and H. W. Egan Bell Syst. Tech. F. $1958,37,739$

6 E. Raub, Metalloberfläche, 1953, 7, A17

7 U. Mayer, Metalloberfiäche, 1974, 28, 59

8 M. Dettke and E. Riedel, Oberfläche-Surface, 1973, 14, 130

9 F. I. Nobel, D. W. Thomson and I. M. Leibel, Plating, 1973, 60,720

10 A. J. Solomon and M. Antler, Proc. 5th Int. Conf. Elect. Contact Phen., 1970, 44

11 G. Horn and W. Merl, Proc. 6th Int. Conf. Elect. Contact Phen., 1972, 65

\title{
The Wear of Electrodeposited Alloy Golds
}

A year ago J. W. Souter of Plessey Interconnect, Northampton, England, described an investigation of the wear characteristics of four types of gold electrodeposits as exhibited in a widely used forty-way plug and socket printed circuit connector (Gold Bulletin, $1974,7,(1), 12)$. In a further paper, presented to the International Electronic Packaging and Production Conference at Brighton, the author now reports on an extension of this investigation into the more complex methods of wear in four types of alloy gold deposits.

The wear resistance of a 17 per cent nickel-gold from an acid cyanide bath was found to be extremely good, but corrosion resistance was highly variable, with cracks penetrating to the basis metal. A 34 per cent silver-gold deposit from an alkaline cyanide electrolyte, despite a reasonably high hardness, showed very poor resistance to wear, resembling the behaviour of the sulphite golds previously reported.

The incorporation into a sulphite gold of 3 per cent copper and 5 per cent palladium greatly reduced galling and wear but the presence of copper naturally rendered the alloy prone to oxidation at around $125^{\circ} \mathrm{C}$. The fourth type, a 34 per cent copper-gold alloy, also from a sulphite bath, showed similar wear characteristics to the palladium-copper-gold-local platelet stripping-but failed in corrosion testing although showing a lesser degree of attack than the silver-gold and nickel-gold alloys.

The author concludes that while copper is effective in improving the wear resistance of sulphite deposits it severely reduces the inherent corrosion and oxidation resistance of gold. 